16 a 18 de outubro de 2019 - Campinas | Brasil

\title{
Desenvolvimento do protótipo em escala de um veiculo agrícola não tripulado
}

\section{Bruno S. Cerqueira*, Angel P. Garcia, Hugo R. Fernandes}

\section{Resumo}

Para aumentar a eficiência da produção agrícola (principalmente as de média escala) é necessário o uso de máquinas autônomas. Com isso, o objetivo deste trabalho foi desenvolver um protótipo de veículo agrícola não tripulado. Para a simulação da estrutura utilizou-se o método de elementos finitos, nestes testes simulou-se uma 'perna', observando as condições críticas de operação. Assim foi possível dimensionar a geometria das peças para a carga de projeto.

\section{Palavras-chave:}

Veículo agrícola, Implemento agrícola, Automação na agricultura.

\section{Introdução}

Comercialmente as máquinas agrícolas são desenvolvidas para grandes produtores, deixando as pequenas propriedades sem condições de adquirir equipamentos, devido aos elevados custos embarcados. Assim, surge a necessidade de projetar máquinas menores. Logo, o objetivo deste trabalho foi projetar o protótipo de um veículo agrícola não tripulado (Figura 1) e, por meio de simulações (utilizando o método de elementos finitos), observar comportamento de uma das 'pernas' em situações críticas.

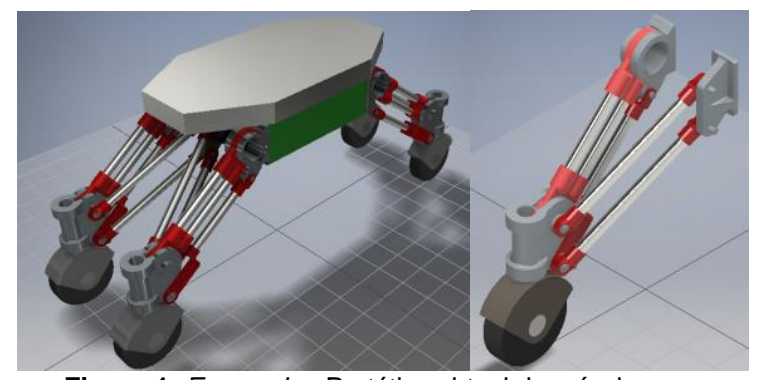

Figura 1. Esquerda - Protótipo virtual do veículo. Direita - Perna para simulação.

\section{Resultados e Discussão}

Realizaram-se simulações utilizando o software Autodesk Inventor, com três cenários (ângulo de trabalho de $77^{\circ}, 90^{\circ}$ e $\left.135^{\circ}\right)$. Observou-se as reações nas 'pernas' dianteira e traseira. As solicitações nos pneus são mostradas na Tabela 1:

\begin{tabular}{llc}
\multicolumn{2}{c}{ Tabela 1. Ações solicitantes a cada 'perna' do veículo } \\
\hline \multicolumn{1}{c}{ Cor } & \multicolumn{1}{c}{ Força } & Magnitude [N] \\
\hline Vermelha & Resistência ao rolamento & 500 \\
Amarela & Ação devido inclinação & 600 \\
Verde & Reação da carga & 1250 \\
\hline
\end{tabular}

Os resultados das tensões de Von Mises são apresentados na Figura 2.

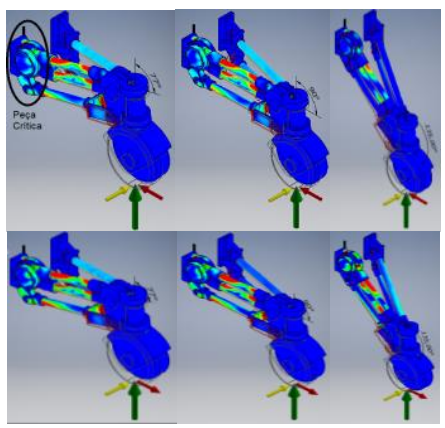

Figura 2. Tensões de Von Mises para 'Perna' dianteira (superior) e para a 'Perna' traseira (inferior) do veículo. Em destaque: peça crítica.
Os valores para os momentos fletores máximos e tensões máximas de Von Mises solicitantes são mostrados na Figura 3 a seguir. Que se observou no mancal de apoio da 'perna' com o chassi, indicado na Figura 2.
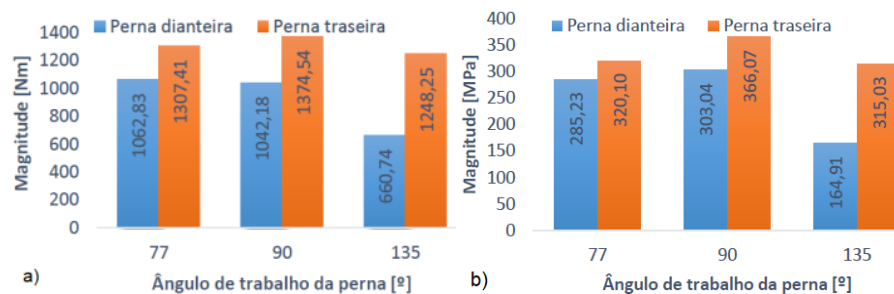

Figura 3. (a) Momento fletor máximo; (b) Tensão máxima de Von Mises

Esses dados foram utilizados para a seleção dos materiais de cada peça do protótipo. No caso da peça crítica no momento crítico: momento fletor de $1400 \mathrm{Nm}$; força cortante de $2400 \mathrm{~N}$ e tensão de Von Mises de 380 Mpa.

A Figura 4 mostra o protótipo da 'perna' do veículo construída em escala (suas peças foram construídas através da tecnologia FDM Fused Deposition Modeling). A estrutura a qual ela está acoplada foi montada com perfis de alumínio.

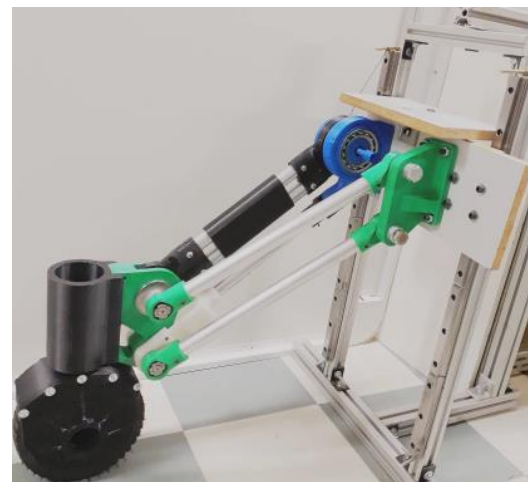

Figura 4. Estrutura do protótipo da 'perna' do veículo.

\section{Conclusões}

Os resultados obtidos mostram que o protótipo da 'perna' do veículo construída é suficiente para os testes em situações reais de campo.

\section{Agradecimentos}

Ao Professor orientador, aos alunos de mestrado e doutorado dos projetos; à FEAGRI pelo espaço concedido e ao Centro Nacional de Pesquisa pela bolsa.

BLACKMORE, B. S. et al. A SPECIFICATION FOR AN AUTONOMOUS CROP PRODUCTION MECHANIZATION SYSTEM B.S. Blackmore, S. Fountas, T.A. Gemtos. Life Sciences, v. IX, n. 2000 p. 1-24, 2007. 